\title{
Improved rates of exclusive breastfeeding at 14 weeks of age in KwaZulu Natal, South Africa: what are the challenges now?
}

\author{
C. Horwood ${ }^{1 *}$, L. Haskins ${ }^{1}$ (D, IM Engebretsen² ${ }^{2}$ S. Phakathi ${ }^{1}$, C. Connolly ${ }^{1}$, A. Coutsoudis ${ }^{3}$ and L. Spies ${ }^{4}$
}

\begin{abstract}
Background: Increasing the rate of exclusive breastfeeding (EBF) to $50 \%$ in the first six months of life is one of six major global targets set by the United Nations Decade of Nutrition, and is essential to achieve the sustainable development goals to eradicate hunger and end malnutrition by 2030.

Methods: A survey using multistage random sampling design included 99 primary health care (PHC) clinics in all 11 districts in KwaZulu-Natal (KZN). All mothers and caregivers of infants 14 weeks of age attending the clinics in the study period were requested to participate in a structured interview to explore feeding practices since birth. As non-maternal caregivers may not have detailed knowledge of feeding practices, they provided limited information about current feeding practices. Respondents who consistently reported giving no other food or fluids except breastmilk since birth were classified as practising exclusive breastfeeding (EBF), and those who were currently breastfeeding but had given other food or fluids since birth were categorised as practising mixed breastfeeding (MBF).
\end{abstract}

Results: A total of 4172 interviews were conducted with mothers and caregivers of 14 week old infants. Among mothers 49.8\% were EBF, 23.1\% were MBF and 27.0\% were not breastfeeding. Among non-maternal caregivers $11.8 \%$ reported EBF, 23.4\% MBF and 62.3\% were not giving breastmilk. Higher education (OR 0.6, 95\% Cl 0.4-0.8) and being in the highest socio-economic tertile (OR 0.7, 95\% Cl 0.6-0.9) were risk factors for not practising EBF, while returning to work (OR 0.3, 95\% Cl 0.2-0.3) or school (OR $0.295 \% \mathrm{Cl}, 0.1-0.3)$ was associated with less EBF. HIV-positive mothers were more likely to have never started breastfeeding (OR 3.6,95\% Cl 2.7-4.8). However, they were similar in having stopped breastfeeding by 14 weeks (OR 1.1, 95\% Cl 0.9-1.4) compared to HIV-negative mothers, and, they had similar rates of EBF at 14 weeks of age (OR 1.0, 95\% Cl 0.9-1.3).

Conclusions: Estimates of breastfeeding practices at 14 weeks in KZN are higher than previously shown. However, particular challenges that should be addressed if international targets for EBF are to be achieved include improving breastfeeding practices of HIV positive mothers and supporting all mothers, particularly working or schooling mothers to continue giving breastmilk while they are away from their children.

Keywords: Exclusive breastfeeding, Breastfeeding, Risk factors, HIV infection, South Africa

\footnotetext{
* Correspondence: horwoodc@ukzn.ac.za

${ }^{1}$ Centre for Rural Health, University of KwaZulu-Natal, Durban, South Africa

Full list of author information is available at the end of the article
}

(c) The Author(s). 2018 Open Access This article is distributed under the terms of the Creative Commons Attribution 4.0 International License (http://creativecommons.org/licenses/by/4.0/), which permits unrestricted use, distribution, and reproduction in any medium, provided you give appropriate credit to the original author(s) and the source, provide a link to the Creative Commons license, and indicate if changes were made. The Creative Commons Public Domain Dedication waiver (http://creativecommons.org/publicdomain/zero/1.0/) applies to the data made available in this article, unless otherwise stated. 


\section{Background}

Increasing the rate of exclusive breastfeeding (EBF) in the first six months of life to $50 \%$ is one of six major global targets set by the United Nations (UN) Decade of Nutrition [1], and improving exclusive and sustained breastfeeding rates is essential for achieving sustainable development goals (SDGs) to eradicate hunger and end malnutrition by 2030 [2]. If implemented globally at near universal levels (>90\%), optimal breastfeeding practices could reduce global child deaths by more than 800,000 [3], which makes breastfeeding the most effective preventive intervention to improve infant mortality [4]. The numerous benefits of breastfeeding continue to accrue throughout childhood and into adulthood, including reduced morbidity from diarrhoeal and respiratory illness [5], and reduced risk of overweight and obesity in children, another of the six UN targets [1, 6]. Although long term follow-up studies on infant feeding practices have implicit methodological challenges [7], the favourable effect of breastfeeding on cognitive performance indicators has recently been presented $[8,9]$. In addition, mothers benefit from breastfeeding as longer duration of breastfeeding substantially reduce risk of breast and ovarian cancer [10]. Although investing in interventions to promote and support breastfeeding comes with a cost, this cost should be balanced against reduced mortality and morbidity and increased productivity, which generate short and long-term financial benefits [11].

WHO infant and young child feeding guidelines recommend early initiation of breastfeeding within one hour of birth, EBF for the first six months, followed by sustained breastfeeding for two years and beyond, with introduction of nutritionally-adequate and safe complementary feeding from six months of age [12]. Despite increasing recognition of the benefits of breastfeeding across all settings and income levels, breastfeeding rates remain low in many countries. Rates of EBF among children under 6 months in low- and middle- income countries was estimated at $37 \%$ in 2013, resulting in substantial lost benefits for mothers and children [11]. In South Africa (SA), EBF rates among infants aged under 6 months was found to be $31.6 \%$ in the most recent Demographic and Health survey conducted in 2016 [13], which demonstrates substantial improvements from the previous estimate of $7 \%$ in 2003 [14]. However, early cessation of breastfeeding, mixed feeding and addition of complementary feeds in the first six months, remains the norm among South African mothers [15, 16], and there are few valid estimates of age-specific breastfeeding rates.

A number of factors have been identified as barriers to exclusive and sustained breastfeeding, including sociocultural, health system, community and individual factors [11]. Lack of maternal self-efficacy, poor experiences of breastfeeding and perceptions of insufficient milk are important individual-level barriers to breastfeeding $[11,16]$. Provision of breastfeeding support from health workers, community health workers, peer supporters and others in the family or community have consistently been associated with improved feeding practices $[11,17,18]$. Returning to work after the birth of the infant is a major barrier to breastfeeding and is significantly associated with lower rates of breastfeeding, earlier cessation of breastfeeding, and mothers planning to return to work are less likely to plan to EBF [19-21].

In addition, South Africa has some of the highest rates of HIV infection in the world, with $29.7 \%$ of women attending government antenatal clinics testing HIV positive in 2013, this is highest in KwaZulu Natal province (KZN) where antenatal HIV seroprevalence was $40.1 \%$ in 2013 [22]. In the past decade frequent changes to the HIV and infant feeding guidelines has resulted in the promotion of changing and, at times, contradictory infant feeding messages, some of which were not supportive of breastfeeding [23]. It was not until 2016 that HIV and infant feeding guidelines were revised, so that current feeding advice for HIV exposed infants is similar to that for all infants [24].

In this paper we report the findings of a large survey of infant feeding practises at 14 weeks of age among all infants attending the clinics in KwaZulu-Natal, South Africa and describe determinants of any breastfeeding and EBF at 14 weeks of age in our setting.

\section{Methods}

A quantitative survey was conducted among infant mother/ caregiver pairs attending primary health care (PHC) clinics in all 11 districts in $\mathrm{KZN}$. Immunisation coverage in $\mathrm{KZN}$ is high with $89.9 \%$ children fully immunised at one year in 2014/15 [25], thus this sample could be considered similar to the whole population of infants at this age [26].

All 536 fixed and mobile PHC clinics in KZN were included in the sampling frame. Health facilities in each district were selected for inclusion in the study using multistage stratified random sampling. All caregivers aged 15 years or above attending participating clinics with an infant aged 13- < 16 weeks (91-111 days) were eligible to participate during the inclusion period, including maternal and non-maternal caregivers. Since non-maternal caregivers could not be expected to have accurate information about the mother's situation, they were asked a small number of questions regarding current feeding practices only. Trained field workers used a tablet-based data collection system to collect data from all eligible caregivers.

\section{Sample size}

Since estimates at the district level were wanted, the sample size requirement was stratified by district, and 
the primary sampling unit was the clinic. In the first stage, nine clinics were randomly selected from a list of all clinics providing immunisations in $\mathrm{KZN}$, in each of 11 districts (total 99 clinics). The sample size was calculated using the formula, $n=\mathrm{Z} 2 \mathrm{pq} / \mathrm{d} 2$ (where $\mathrm{Z}=1.96$ at $95 \%$ confidence; $p=$ proportion who are exclusively breastfeeding, $q=1-\mathrm{p} ; \mathrm{d}=$ absolute precision). For this study, we presumed that $p<=0.4$ based on previous routine data and literature; $q=0.6$; precision $(\mathrm{d})=+/-5 \%$. This yielded a required sample size of 369 per district. The final sample size required was thus $369^{*} 11=4059$ respondents.

In the second stage of sampling all eligible mothers attending the clinic within the study period were approached for participation. Data collection continued in all selected clinics in each district contemporaneously until the required sample was realised for that district therefore resulting in a self-weighted sample.

\section{Data management and analysis}

Data were collected using android devices and uploaded to a centralised server in real time using proprietary software. Extensive data quality checks were conducted to ensure data completeness and validity.

The classification of rurality is based on definitions provided by the KZN Department of Cooperative Governance and Traditional Affairs (KZN-COGTA), which segments the KwaZulu Natal province into 5 distinct categories. Clinics in areas A, B1 and B2 (metro's, secondary cities and large towns) were designated as urban, whereas areas B3 and B4 (small towns and mainly rural) were designated as rural [27].

Mothers were asked questions about feeding practices since birth, including a question about ever having given other food or fluids to the infant, and later follow-up questions specifically asked about whether the infant had ever been given formula milk, and whether any pre-lacteal feeds were given. Only those who were breastfeeding and consistently reported having given no other food or fluids, except breastmilk, were classified as exclusively breastfeeding (EBF). Those who reported currently breastfeeding but who reported giving other food or fluids at any time since birth, were categorised as mixed breastfeeding (MBF). Non-maternal caregivers were categorised as EBF if the carer reported that the infant had never been given any other food or fluids other than breastmilk.

Data processing and analysis was conducted using Stata 13.1 (StataCorp. 2013. Stata Statistical Software: Release 13. College Station, TX: StataCorp LP.) Given the multiple stage sampling design, Stata's survey settings ("svyset \{pweight=wgt], strata (district) psu(clinic)" was used make provincial level estimates and the appropriate 95\% confidence intervals (95\% CIs). This analysis includes both mothers and non-maternal caregivers presenting data on infant feeding characteristics at 14 weeks, the social and economic circumstances of caregivers as well as local infrastructure. However, due to the limited information available from the non-maternal carers, only the sub-set with mothers was included in the risk factor regression analysis on factors associated with any breastfeeding and EBF.

Logistic regression analysis was done for two dependent variables using unweighted data but adjusted for study design. First, any breastfeeding versus non-breastfeeding, and second EBF versus mixed and non-breastfeeding. This was to see if EBF had a similar associated risk pattern to any breastfeeding in general. Crude and adjusted models are presented. For the adjusted models, factors significant at $p<0.2$ at the bivariable level or reported in the literature were included in the model. The overall likelihood ratio test (Wald statistic) was assessed for both regression models. For post-hoc model testing, the linktest was used to test the model specification, and the Hosmer-Lemeshow test for goodness-of-fit was used to determine how well the model fit. Linearity was tested using lowess smoothing. The area under the ROC curve for the breastfeeding model was used to determine whether sensitivity and specificity was acceptable.

Principle components analysis (PCA) was used to created socio-economic quintiles. Factors included were household assets and wall material of household (traditional or brick). The PCA scores were categorized into low, medium and high tertiles.

\section{Results}

A total of 4172 interviews were conducted with caregivers attending 78 fixed and 21 mobile clinics in 11 districts of KZN between May 2014 and March 2015. Among the infants $3659 / 4172(87.7 \%)$ attended with the mother and 513 (12.3\%) attended with a carer who was not the mother (Table 1). The target age of the infant was 14 weeks, coinciding with the scheduled 14 -week vaccination visit. The median, intra-quartile-range (IQR), age of the child was 102 days (IQR 98-106).

Characteristics of participating mothers are shown in Table 2. The geographical location and population group characteristics were similar to those of all caregivers. The median age of 3659 participating mothers was 24 years (IQR 20-29 years), amongst whom 52 mothers (1.4\%) reported that they did not stay in the same house as the infant. Most mothers reported that they were in a relationship with the father of the child $3244 / 3659$ (88.7, 95\% CI 87.6-89.6\%), and 874/3659 (23.9, 95\% CI 22.5-25.3\%) mothers were living in the same house as the father of the child. Around half of all fathers had completed high school 1887/3659 (51.6, 95\% CI 50.0-53.2\%), and more than half of the fathers were employed 2393/ 3659 (65.4, 95\% CI 63.8-66.9) and had provided regular support for the infant since birth, including providing 
Table 1 Characteristics of all participating child carers

\begin{tabular}{|c|c|c|c|}
\hline & $N(4172)$ & $\%$ & $95 \% \mathrm{Cl}$ \\
\hline \multicolumn{4}{|l|}{ Relationship with the child } \\
\hline Mother & 3659 & 87.7 & $(86.7-88.7)$ \\
\hline Grandmother & 196 & 4.7 & $(4.1-5.4)$ \\
\hline Father & 36 & 0.9 & $(0.6-1.2)$ \\
\hline Other relative & 203 & 4.9 & $(4.3-5.6)$ \\
\hline Non relative caregiver & 78 & 1.9 & $(1.5-2.3)$ \\
\hline \multicolumn{4}{|l|}{ Population group } \\
\hline African & 4094 & 98.1 & $(97.7-98.5)$ \\
\hline Coloured & 19 & 0.5 & $(0.3-0.7)$ \\
\hline Indian origin & 46 & 1.1 & $(0.8-1.5)$ \\
\hline White & 13 & 0.3 & $(0.2-0.54)$ \\
\hline Sex of baby (\% male) & 2045 & 49.0 & $(47.5-50.5)$ \\
\hline Geographic area (rural) & 2845 & 68.2 & $(66.8-69.6)$ \\
\hline
\end{tabular}

money and other goods 2255/3659 (61.6, 95\% CI 60.0$63.2 \%)$.

\section{Contact with the health service}

Although most participating mothers attended antenatal clinics 3554/3659 (97.1\%), some mothers 610/3554 (17.1\%) reported that they did not receive any infant feeding advice during their antenatal clinic visits. Similarly, although most participating mothers delivered their infant in a health facility 3494/3659 (95.5\%), some did not receive breast feeding advice while at the facility 791/3494 (22.6\%). Most mothers reported that the infant was placed skin-to-skin after delivery 2404/3569 (65.7\%), but less than half $1587 / 3659$ (43.4\%) of the mothers reported that they had initiated breastfeeding within one hour of delivery.

In regards to community based services, 391/3659 (9.4\%) mothers reported receiving a visit from a community health worker (CHW) during pregnancy, and 453/3659 (10.9\%) mothers reported receiving a visit from a $\mathrm{CHW}$ after delivery.

\section{Infant feeding practices}

Reported current feeding practices among all participants, both non-maternal caregivers and mothers are shown in Table 3. Among 513 non-maternal caregivers, $154\left(35.3 \%_{\mathrm{wgt}}, 95 \% \mathrm{CI}_{\mathrm{adj}}\right.$ : $\left.28.7-42.4\right)$ reported that the infant was currently receiving breastmilk. Of those, 85/154 $\left(39.9 \%_{\text {wgt }}, 95 \%\right.$ CI sfj $_{26.0-55.6)}$ non-maternal caregivers reported feeding the infant with expressed breastmilk during the clinic visit. Most mothers, 2705/ 3659 (73.0\% wgt, 95\% CI adj: 69.5-76.2) reported that they were currently breastfeeding (either mixed breastfeeding or EBF).
Table $\mathbf{2}$ Characteristics of participating mothers and infants

\begin{tabular}{|c|c|c|c|}
\hline & $N=3659$ & $\%$ & $95 \% \mathrm{Cl}$ \\
\hline \multicolumn{4}{|l|}{ Mothers age } \\
\hline$<20$ years & 702 & 19.2 & $(17.9-20.5)$ \\
\hline 20-24 years & 1191 & 32.6 & $(31.0-34.1)$ \\
\hline $25-29$ years & 858 & 23.5 & $(22.1-24.9)$ \\
\hline$>30$ years & 908 & 24.8 & $(23.4-26.2)$ \\
\hline \multicolumn{4}{|l|}{ Population group } \\
\hline African & 3604 & 98.5 & $(98.0-98.8)$ \\
\hline Coloured & 14 & 0.4 & $(0.2-0.6)$ \\
\hline Indian origin & 30 & 0.8 & $(0.6-1.2)$ \\
\hline White & 11 & 0.3 & $(0.2-0.5)$ \\
\hline \multicolumn{4}{|l|}{ Education } \\
\hline Primary school or less & 324 & 8.9 & $(8.0-9.8)$ \\
\hline Completed Grades 8 to 11 & 1884 & 51.5 & $(49.9-53.1)$ \\
\hline Complete Grade 12 or higher & 1451 & 39.7 & $(38.1-41.3)$ \\
\hline Returned to school since infant was born & 246 & 6.7 & $(6.0-7.6)$ \\
\hline \multicolumn{4}{|l|}{ Work } \\
\hline $\begin{array}{l}\text { Mother has done no paid work in past } \\
12 \text { months }\end{array}$ & 2779 & 75.9 & $(74.5-77.3)$ \\
\hline $\begin{array}{l}\text { Mother has done paid work in past } \\
12 \text { months but not since infant was born }\end{array}$ & 584 & 16.0 & $(14.8-17.2)$ \\
\hline $\begin{array}{l}\text { Mother has done paid work since infant } \\
\text { was born }\end{array}$ & 296 & 8.1 & $(7.2-9.0)$ \\
\hline \multicolumn{4}{|l|}{ Financial support (multiple sources) } \\
\hline $\begin{array}{l}\text { Mother receives child support grant } \\
\text { for any child }\end{array}$ & 2445 & 66.8 & $(65.3-68.3)$ \\
\hline $\begin{array}{l}\text { Mother receives maternity grant/pay } \\
\text { from employer }\end{array}$ & 137 & 3.7 & $(3.2-4.4)$ \\
\hline Mother receives disability grant & 22 & 0.6 & $(0.4-0.9)$ \\
\hline $\begin{array}{l}\text { Mother receives maintenance/money } \\
\text { from partner }\end{array}$ & 2456 & 67.1 & $(65.6-68.6)$ \\
\hline $\begin{array}{l}\text { Mother receives money from } \\
\text { family members }\end{array}$ & 1196 & 32.7 & $(31.2-34.2)$ \\
\hline Household geographic area (rural) & 2498 & 68.3 & $(66.7-69.8)$ \\
\hline Has more than one child & 2010 & 54.9 & $(53.3-56.5)$ \\
\hline Sex of infant (\% male) & 1802 & 49.2 & $(47.6-50.9)$ \\
\hline
\end{tabular}

\section{HIV positive mothers}

Of the 3659 mothers surveyed, 3567 (97.5\%) had been tested for HIV and were able to report their HIV status; 55 mothers chose not to answer the HIV questions; eight mothers had never had an HIV test and data were missing for 29 mothers.

Of those mothers who reported their HIV status, 1274/ 3567 (34.8) were HIV positive, of whom 1134 (89.0\%) reported currently taking antiretroviral treatment. The bi- and multivariable analysis showed that HIV positive mothers were less likely to be currently breastfeeding (OR 0.5, 95\% CI 0.4-0.6) (Table 4) but they had similar rates of EBF at 14 weeks of age (adjusted OR 1.2, 95\% CI 
Table 3 Reported feeding practices among all carers, non-maternal and maternal carers

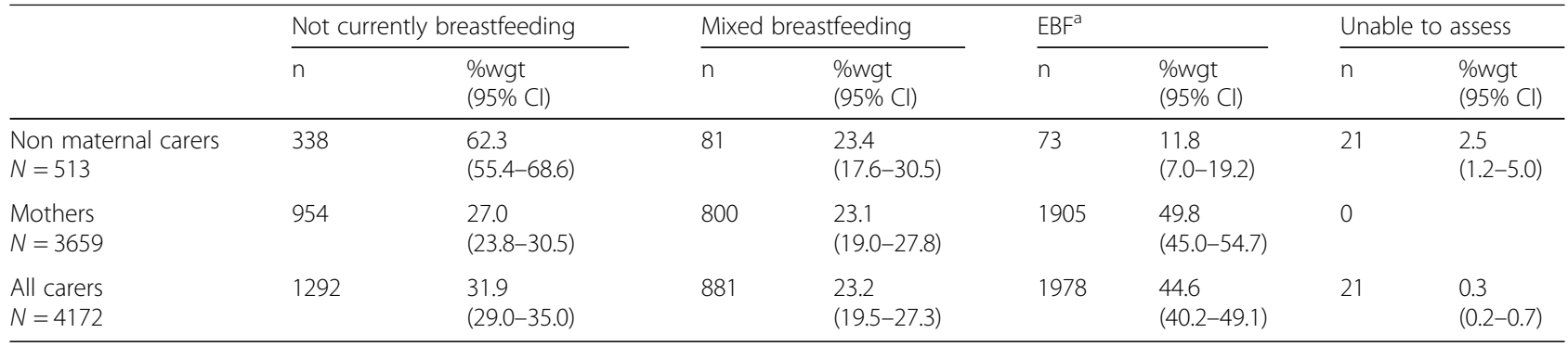

${ }^{a}$ Exclusive breastfeeding

0.96-1.4) (Table 5) when compared to HIV negative mothers. HIV positive mothers were far more likely to have never started breastfeeding (OR 3.6, 95\% CI 2.7-4.8). They were similar in having stopped breastfeeding at 14 weeks (OR 1.1, 95\% CI 0.9-1.4). Feeding practices according to HIV status are shown in Fig. 1.

\section{Returning to work or school}

Feeding practises among mothers who had returned to work or school at the time of the interview are shown in Fig. 1.

\section{Factors associated with any breastfeeding at 14 weeks}

According to a multi-variable analysis the following factors were associated with not breastfeeding at week 14: older mothers, mothers with more education, urban mothers, richer households, including those with electricity, having returned to work and school, and being HIV positive or having an unknown HIV status (Table 4). Antenatal care advice in the clinics as well as by community health workers were protective factors, and early initiation of breastfeeding and breastfeeding assistance and support were also identified as protective factors for any breastfeeding at 14 weeks.

\section{Factors associated with exclusive breastfeeding}

There was a similar pattern of risk- and protective factors shown for exclusive breastfeeding versus any other feeding as was seen as for any breastfeeding in general (Table 5), where higher education and being in the highest socio-economic tertile were risk factors for not exclusively breastfeeding. However, returning to work (OR 0.3, 95\% CI 0.2-0.3) and school (OR 0.2 95\% CI, 0.1-0.3) were most strongly associated with less exclusive breastfeeding. Breastfeeding advice at the antenatal care clinics came out most strongly (OR 1.5, 95\% CI 1.2-2.0) followed by advice in the communities as well as early initiation of breastfeeding and assistance with initiating breastfeeding as protective factors. Skin-to-skin contact after delivery was a protective factor for exclusive breastfeeding (OR 1.3, 95\% CI 1.0-1.5), rather than for any breastfeeding (Tables 4 and 5 ).

\section{Discussion}

This study provided estimates of feeding practices at 14 weeks of age among infants attending a random selection of clinics in KwaZulu-Natal, South Africa, including those attending with non-maternal caregivers and with mothers. Further, it presents factors associated with any breastfeeding and exclusive breastfeeding among mothers, and shows that working or schooling mothers and those who are HIV infected have quite different feeding practices compared to other mothers. The survey design included a feeding recall since birth, which allowed for categorisation of infant feeding practices up to the interview time point into non-breastfeeding, mixed breastfeeding and exclusive breastfeeding. The study did not consider "lapses" and/or "switches" of feeding category, so information on any feeding behaviour since birth accumulated to the current feeding category. This is the strictest definition we have of exclusive breastfeeding [28, 29], meaning that no other feeds had been given up to the time of interview other than breast milk and prescribed medicines, drops or syrups [30]. Most previous published reports of EBF rates in SA have been based on a $24 \mathrm{~h}$ or seven day feeding recall, which is a less strict definition of exclusive breastfeeding [31] or report rates of breastfeeding among all children under 6 months [32]. The rigorous methodology employed in our study suggests that exclusive breastfeeding until 14 weeks of age has improved substantially in $\mathrm{KZN}$, a trend that is supported by other recently reported data from across South Africa [31, 33, 34]. This may suggest that interventions to support breastfeeding, including the Tshwane declaration made by the South African Department of Health in 2011 [35] and changes to infant feeding recommendations for HIV infected women that support breastfeeding, may have resulted in improvements to breastfeeding rates. Although these results are encouraging, further improvements are still required.

The multi-variable regression analysis identified key risk-and protective factors associated with the respective feeding categories. The most striking finding was that being older, having higher education, going back to work or school, and being in a higher socioeconomic tertile was associated with less breastfeeding at 14 weeks, and 
Table 4 Factors associated with any breastfeeding vs non-breastfeeding (non-BF) among participating mothers, $N=3659$, bi- and multi-variable logistic analysis

\begin{tabular}{|c|c|c|c|c|c|c|c|c|c|}
\hline \multirow[b]{2}{*}{ Risk Factors } & \multicolumn{2}{|c|}{ Non-BF } & \multicolumn{2}{|l|}{ BF } & \multirow{2}{*}{$\begin{array}{l}\text { Total } \\
\mathrm{n}\end{array}$} & \multicolumn{2}{|c|}{ bi variable } & \multicolumn{2}{|c|}{ multi-variable } \\
\hline & $n$ & $\%$ & $n$ & $\%$ & & $\overline{O R}$ & $95 \% \mathrm{Cl}$ & $\mathrm{OR}$ & $95 \% \mathrm{Cl}$ \\
\hline \multicolumn{10}{|l|}{ Age of the mother } \\
\hline$<20$ & 147 & 20.9 & 555 & 79.1 & 702 & ref & & ref & \\
\hline $20-29$ & 511 & 24.9 & 1538 & 75.1 & 2049 & 0.8 & $(0.6-0.9)$ & 0.8 & $(0.7-1.1)$ \\
\hline $30-49$ & 296 & 32.6 & 612 & 67.4 & 908 & 0.5 & $(0.4-0.7)$ & 0.6 & $(0.5-0.9)$ \\
\hline \multicolumn{10}{|l|}{ Education level } \\
\hline $0-7$ & 53 & 16.4 & 271 & 83.6 & 324 & ref & & Ref & \\
\hline $8-11$ & 437 & 23.2 & 1447 & 76.8 & 1884 & 0.6 & $(0.5-0.9)$ & 0.7 & $(0.5-0.9)$ \\
\hline 12 & 460 & 32.0 & 977 & 68.0 & 1437 & 0.4 & $(0.3-0.6)$ & 0.4 & $(0.3-0.6)$ \\
\hline \multicolumn{10}{|l|}{ Geographic area } \\
\hline Rural & 573 & 22.9 & 1925 & 77.1 & 2498 & ref & & ref & \\
\hline Urban & 381 & 32.8 & 780 & 67.2 & 1161 & 0.6 & $(0.5-0.8)$ & 0.8 & $(0.7-1.0)$ \\
\hline \multicolumn{10}{|c|}{ Household connected to electricity } \\
\hline No & 118 & 16.0 & 618 & 84.0 & 736 & ref & & ref & \\
\hline Yes & 835 & 28.6 & 2087 & 71.4 & 2922 & 0.5 & $(0.4-0.6)$ & 0.7 & $(0.5-0.9)$ \\
\hline \multicolumn{10}{|c|}{ Socioeconomic quintile } \\
\hline 1 (Low) & 223 & 18.3 & 997 & 81.7 & 1220 & ref & & ref & \\
\hline 2 & 283 & 23.2 & 937 & 76.8 & 1220 & 0.7 & $(0.6-0.9)$ & 1.0 & $(0.8-1.3)$ \\
\hline 3 (high) & 448 & 36.8 & 771 & 63.2 & 1219 & 0.4 & $(0.3-0.5)$ & 0.7 & $(0.5-0.9)$ \\
\hline \multicolumn{10}{|l|}{ Mother working } \\
\hline No/never & 780 & 23.2 & 2583 & 76.8 & 3363 & ref & & Ref & \\
\hline Returned work & 174 & 58.8 & 122 & 41.2 & 296 & 0.2 & $(0.2-0.3)$ & 0.3 & $(0.2-0.4)$ \\
\hline \multicolumn{10}{|c|}{ Mother returned to school since birth } \\
\hline No/not in school & 855 & 25.1 & 2558 & 74.9 & 3413 & ref & & ref & \\
\hline Yes & 99 & 40.2 & 147 & 59.8 & 246 & 0.5 & $(0.4-0.7)$ & 0.2 & $(0.2-0.3)$ \\
\hline \multicolumn{10}{|l|}{ HIV status } \\
\hline Negative & 488 & 21.3 & 1805 & 78.7 & 2293 & ref & & ref & \\
\hline Positive & 435 & 34.1 & 839 & 65.9 & 1274 & 0.5 & $(0.4-0.6)$ & 0.5 & $(0.4-0.6)$ \\
\hline Unknown & 31 & 33.7 & 61 & 66.3 & 92 & 0.5 & $(0.3-0.9)$ & 0.7 & $(0.4-1.0)$ \\
\hline \multicolumn{10}{|c|}{ Feeding advice given at ANC clinic } \\
\hline No & 189 & 31.0 & 421 & 69.0 & 610 & ref & & ref & \\
\hline Yes & 765 & 25.1 & 2284 & 74.9 & 3049 & 1.3 & $(1.1-1.7)$ & 1.4 & $(1.1-1.8)$ \\
\hline \multicolumn{10}{|c|}{ Feeding advice given at delivery } \\
\hline No & 206 & 26.0 & 585 & 74.0 & 791 & ref & & ref & \\
\hline Yes & 748 & 26.1 & 2120 & 73.9 & 2868 & 1.0 & $(0.8-1.2)$ & 0.8 & $(0.7-1.0)$ \\
\hline \multicolumn{10}{|c|}{ Infant placed skin-to-skin after delivery } \\
\hline No & 347 & 27.6 & 908 & 72.4 & 1255 & ref & & ref & \\
\hline Yes & 607 & 25.2 & 1797 & 74.8 & 2404 & 1.1 & $(0.9-1.4)$ & 0.98 & $(0.8-1.2)$ \\
\hline \multicolumn{10}{|c|}{ Initiated breastfeeding within $1 \mathrm{~h}$ of delivery } \\
\hline No & 644 & 31.1 & 1428 & 68.9 & 2072 & ref & & ref & \\
\hline Yes & 310 & 19.5 & 1277 & 80.5 & 1587 & 1.9 & $(1.5-2.2)$ & 1.7 & $(1.5-2.1)$ \\
\hline
\end{tabular}


Table 4 Factors associated with any breastfeeding vs non-breastfeeding (non-BF) among participating mothers, $N=3659$, bi- and multi-variable logistic analysis (Continued)

\begin{tabular}{|c|c|c|c|c|c|c|c|c|c|}
\hline \multirow[b]{2}{*}{ Risk Factors } & \multicolumn{2}{|c|}{ Non-BF } & \multicolumn{2}{|l|}{$\mathrm{BF}$} & \multirow{2}{*}{$\begin{array}{l}\text { Total } \\
\mathrm{n} \\
\end{array}$} & \multicolumn{2}{|c|}{ bi variable } & \multicolumn{2}{|c|}{ multi-variable } \\
\hline & $n$ & $\%$ & $n$ & $\%$ & & $\mathrm{OR}$ & $95 \% \mathrm{Cl}$ & $\mathrm{OR}$ & $95 \% \mathrm{Cl}$ \\
\hline \multicolumn{10}{|c|}{ Mother helped with breastfeeding initiation } \\
\hline No & 558 & 30.9 & 1250 & 69.1 & 1808 & ref & & & \\
\hline Yes & 396 & 21.4 & 1455 & 78.6 & 1851 & 1.6 & $(1.4-2.0)$ & 1.4 & $(1.2-1.7)$ \\
\hline \multicolumn{10}{|c|}{ Feeding advice by CHW: antenatal } \\
\hline No & 903 & 27.2 & 2417 & 72.8 & 3320 & ref & & ref & \\
\hline Yes & 51 & 15.0 & 288 & 85.0 & 339 & 2.1 & $(1.5-2.9)$ & 1.9 & $(1.3-2.7)$ \\
\hline \multicolumn{10}{|c|}{ Feeding advice by CHW: postnatal } \\
\hline No & 878 & 26.8 & 2403 & 73.2 & 3281 & ref & & ref & \\
\hline Yes & 76 & 20.1 & 302 & 79.9 & 378 & 1.5 & $(1.1-1.9)$ & 1.0 & $(0.7-1.5)$ \\
\hline
\end{tabular}

that this was just as important as being HIV-positive in determining non-breastfeeding. Thus, a key message from this study, is that there is a need to focus on the general hurdles for breastfeeding per se as well as continuing to provide the important support for women with an HIV-positive status.

This study demonstrated clearly that a key challenge to sustaining breastfeeding was when the mother returns to work or school. While WHO has re-emphasized the importance of supporting breastfeeding in the workplace, and returning to work has been shown to be a barrier to optimal breastfeeding practices in many settings [36-39], there remains little evidence that this is translated into public policies at national levels. Only 42 countries among 185 surveyed complied with the recommendations of the International Labour Organisation for a minimum of 18 weeks maternity leave [40]. Breastfeeding can be continued after return to work if supportive policies are in place, including childcare or support for expressing of breastmilk [40, 41], and reducing barriers to breastfeeding can reduce absenteeism and improve motivation among workers [41]. In South Africa, the Basic Conditions of Employment Act provides for four consecutive months of maternity leave but there are no other provisions in the act to support breastfeeding [42].

There are major practical challenges to achieving sustained breastfeeding, particularly exclusive breastfeeding, during work or school and mothers may require considerable support [43, 44]. These challenges include developing skills in expressing breastmilk ahead of the return to work or school, safe storage of expressed breast milk at home and at work, and cup-feeding. It is important for health workers, including $\mathrm{CHWs}$, to be confident in supporting this process. Of note was that many participating mothers in this study reported giving their babies expressed breastmilk at some time when they were away from the infant, which suggests that expressing breastmilk is being practiced in these communities. Almost half of working women in South Africa are working in the informal sector, including domestic workers. These women do not have access to social protection, and are frequently vulnerable and low-paid. More information is needed about informally working women and how breastfeeding could be supported in this setting.

Almost universal attendance at health facilities provides opportunities for health workers to provide appropriate counselling, but many mothers reported having not received feeding advice during their visits, leading to missed opportunities to reinforce key infant feeding counselling messages. Our data suggests that whenever advice is given, this is effective at improving feeding practices, and this observation is supported by other studies [45]. It is crucial that mothers attending the clinic for antenatal care or with an infant, receive infant feeding counselling at every visit. In the postnatal period advice should not just include generic counselling messages but should be individually based and targeted at providing mothers with support for dealing with day-to-day infant feeding challenges [46]. Closing the gaps in feeding advice and assistance at clinic and community level should be a key focus to improve breastfeeding rates.

Our data shows that receiving a CHW visit is effective in improving breastfeeding practices, and this is supported by other studies $[18,47]$. Home visits allow accessible, appropriate, individualised breastfeeding support to be given, and may involve family members if appropriate. Studies suggest that family members and social support of mothers at the household level plays a strong role in influencing feeding practices, so that $\mathrm{CHWs}$ have an important role to play in providing context specific feeding advice and support for mothers experiencing problems sustaining breastfeeding [18]. However, very few mothers in this study reported having received a visit from a $\mathrm{CHW}$, 
Table 5 Factors associated with not exclusive breastfeeding (non-EBF) versus exclusive breastfeeding (EBF) practice among participating mothers, $N=3659$, bi- and multi-variable logistic analysis

\begin{tabular}{|c|c|c|c|c|c|c|c|c|c|}
\hline \multirow[b]{2}{*}{ Risk Factors } & \multicolumn{2}{|c|}{$\underline{\text { Non-EBF }}$} & \multicolumn{2}{|l|}{$\underline{E B F}$} & \multirow{2}{*}{$\begin{array}{l}\text { Total } \\
\mathrm{n} \\
\end{array}$} & \multicolumn{2}{|c|}{ Bi variable } & \multicolumn{2}{|c|}{ Multi variable } \\
\hline & $\mathrm{n}$ & $\%$ & $\mathrm{n}$ & $\%$ & & $\mathrm{OR}$ & $95 \% \mathrm{Cl}$ & OR & $95 \% \mathrm{Cl}$ \\
\hline \multicolumn{10}{|l|}{ Age of the mother } \\
\hline$<20$ & 374 & 53.3 & 328 & 46.7 & 702 & ref & & ref & \\
\hline $20-29$ & 951 & 46.4 & 1098 & 53.6 & 2049 & 1.3 & $(1.1-1.6)$ & 1.1 & $(0.9-1.4)$ \\
\hline $30-49$ & 429 & 47.2 & 479 & 52.8 & 908 & 1.3 & $(1.0-1.6)$ & 1.1 & $(0.8-1.4)$ \\
\hline \multicolumn{10}{|l|}{ Education level } \\
\hline Grades 0-7 & 114 & 35.2 & 210 & 64.8 & 324 & ref & & ref & \\
\hline Grades 8-11 & 882 & 46.8 & 1002 & 53.2 & 1884 & 0.6 & $(0.5-0.8)$ & 0.7 & $(0.6-1.0)$ \\
\hline Grade 12 (completed school) & 758 & 52.2 & 693 & 47.8 & 1451 & 0.5 & $(0.4-0.7)$ & 0.6 & $(0.4-0.8)$ \\
\hline \multicolumn{10}{|l|}{ Geographic area } \\
\hline Rural & 1103 & 44.2 & 1395 & 55.8 & 2498 & ref & & ref & \\
\hline Urban & 651 & 56.1 & 510 & 43.9 & 1161 & 0.6 & $(0.4-0.9)$ & 0.8 & $(0.6-1.0)$ \\
\hline \multicolumn{10}{|l|}{ Household connected to electricity } \\
\hline No & 287 & 39.0 & 449 & 61.0 & 736 & ref & & ref & \\
\hline Yes & 1466 & 50.2 & 1456 & 49.8 & 2922 & 0.6 & $(0.5-0.8)$ & 0.9 & $(0.7-1.2)$ \\
\hline \multicolumn{10}{|l|}{ Socioeconomic tertile } \\
\hline 1 (Low) & 483 & 39.6 & 737 & 60.4 & 1220 & ref & & ref & \\
\hline 2 & 572 & 46.9 & 648 & 53.1 & 1220 & 0.7 & $(0.6-0.9)$ & 0.9 & $(0.7-1.1)$ \\
\hline 3 (high) & 699 & 57.3 & 520 & 42.7 & 1219 & 0.5 & $(0.4-0.6)$ & 0.7 & $(0.6-0.9)$ \\
\hline \multicolumn{10}{|l|}{ Mother working } \\
\hline No/never & 1526 & 45.4 & 1837 & 54.6 & 3363 & ref & & ref & \\
\hline Returned to work & 228 & 77.0 & 68 & 23.0 & 296 & 0.2 & $(0.2-0.3)$ & 0.3 & $(0.2-0.3)$ \\
\hline \multicolumn{10}{|c|}{ Mother returned to school since birth } \\
\hline No/not in school & 1563 & 45.8 & 1850 & 54.2 & 3413 & ref & & ref & \\
\hline Yes & 191 & 77.6 & 55 & 22.4 & 246 & 0.2 & $(0.2-0.3)$ & 0.2 & $(0.1-0.3)$ \\
\hline \multicolumn{10}{|l|}{ HIV status } \\
\hline Negative & 1123 & 49.0 & 1170 & 51.0 & 2293 & ref & & ref & \\
\hline Positive & 577 & 45.3 & 697 & 54.7 & 1274 & 1.2 & $(0.96-1.4)$ & 1.0 & $(0.9-1.3)$ \\
\hline Unknown & 54 & 58.7 & 38 & 41.3 & 92 & 0.7 & $(0.4-1.0)$ & 0.8 & $(0.5-1.3)$ \\
\hline \multicolumn{10}{|l|}{ Feeding advice given at ANC clinic } \\
\hline No & 358 & 58.7 & 252 & 41.3 & 610 & ref & & ref & \\
\hline Yes & 1396 & 45.8 & 1653 & 54.2 & 3049 & 1.7 & $(1.3-2.2)$ & 1.5 & $(1.2-2.0)$ \\
\hline \multicolumn{10}{|l|}{ Feeding advice given at hospital } \\
\hline No & 408 & 51.6 & 383 & 48.4 & 791 & ref & & ref & \\
\hline Yes & 1346 & 46.9 & 1522 & 53.1 & 2868 & 1.2 & $(0.98-1.5)$ & 0.9 & $(0.7-1.1)$ \\
\hline \multicolumn{10}{|c|}{ Infant placed skin-to-skin after delivery } \\
\hline No & 668 & 53.2 & 587 & 46.8 & 1255 & ref & & ref & \\
\hline Yes & 1086 & 45.2 & 1318 & 54.8 & 2404 & 1.4 & $(1.1-1.7)$ & 1.3 & $(1.0-1.5)$ \\
\hline \multicolumn{10}{|c|}{ Initiation of breastfeeding within one hour of delivery } \\
\hline No & 1094 & 52.8 & 978 & 47.2 & 2072 & ref & & ref & \\
\hline Yes & 660 & 41.6 & 927 & 58.4 & 1587 & 1.6 & $(1.3-1.9)$ & 1.4 & $(1.2-1.7)$ \\
\hline
\end{tabular}


Table 5 Factors associated with not exclusive breastfeeding (non-EBF) versus exclusive breastfeeding (EBF) practice among participating mothers, $N=3659$, bi- and multi-variable logistic analysis (Continued)

\begin{tabular}{|c|c|c|c|c|c|c|c|c|c|}
\hline \multirow[b]{2}{*}{ Risk Factors } & \multicolumn{2}{|c|}{ Non-EBF } & \multicolumn{2}{|l|}{$\underline{E B F}$} & \multirow{2}{*}{$\begin{array}{l}\text { Total } \\
\mathrm{n}\end{array}$} & \multicolumn{2}{|c|}{ Bi variable } & \multicolumn{2}{|c|}{ Multi variable } \\
\hline & $n$ & $\%$ & $\mathrm{n}$ & $\%$ & & $\mathrm{OR}$ & $95 \% \mathrm{Cl}$ & $\mathrm{OR}$ & $95 \% \mathrm{Cl}$ \\
\hline \multicolumn{10}{|c|}{ Mother helped with initiation of breastfeeding } \\
\hline No & 919 & 50.8 & 889 & 49.2 & 1808 & ref & & ref & \\
\hline Yes & 835 & 45.1 & 1016 & 54.9 & 1851 & 1.3 & $(1.0-1.5)$ & 1.2 & $(0.95-1.4)$ \\
\hline \multicolumn{10}{|c|}{ Feeding advice by $\mathrm{CHW}$ : antenatal } \\
\hline No & 1636 & 49.3 & 1684 & 50.7 & 3320 & ref & & ref & \\
\hline Yes & 118 & 34.8 & 221 & 65.2 & 339 & 1.8 & $(1.5-2.3)$ & 1.4 & $(1.1-1.8)$ \\
\hline \multicolumn{10}{|c|}{ Feeding advice by $\mathrm{CHW}$ : postnatal } \\
\hline No & 1607 & 49.0 & 1674 & 51.0 & 3281 & ref & & ref & \\
\hline Yes & 147 & 38.9 & 231 & 61.1 & 378 & 1.5 & $(1.2-1.9)$ & 1.1 & $(0.8-1.6)$ \\
\hline
\end{tabular}

Probability of EBF adjusted of study design only (unweighted). Significant associations shown in bold text

although over 11,000 CHWs are employed in KZN to provide services at household level, and a core function of these CHWs is to visit pregnant women and new mothers in their homes, including providing breastfeeding support. The role of CHWs in provision of maternal and child health services needs to be strengthened and closer supervision and mentoring may be necessary.

HIV positive status remains a key determinant of mothers' choosing not to breastfeed. However, the message of avoiding mixed feeding has largely been adhered to by HIV infected mothers. Thus, we found similar rates of exclusive breastfeeding in the HIV positive group as in the HIV negative group, despite there being more non-breastfeeding in the HIV positive group. The most recent WHO HIV and infant feeding guidelines recommend breastfeeding for all, irrespective of HIV status, together with support for anti-retroviral drug adherence among HIV infected women [48]. There is a need for continued breastfeeding promotion and support among
HIV positive women in the light of these new guidelines, which have been adopted in South Africa [48]. A key message that should be promoted is that if EBF cannot be achieved for some mothers and babies, it is still important to sustain as much breastfeeding as possible. This message applies to HIV infected mothers, as long as the mother is compliant with ART and is virally suppressed. This is an area where confusion arises as this is contrary to the strong message provided previously that mixed breastfeeding was unacceptable for HIV infected mothers and the breastfeeding period should be short. This study showed that the 'no mixed feeding message' has been strongly received for HIV positive mothers, but a concern is that fear of mixed feeding could lead HIV positive mothers to either abstain from initiating breastfeeding or stop breastfeeding prematurely. In addition, only $87 \%$ of mothers reporting taking anti-retroviral treatment, highlighting the importance of ART adherence. This means that in this

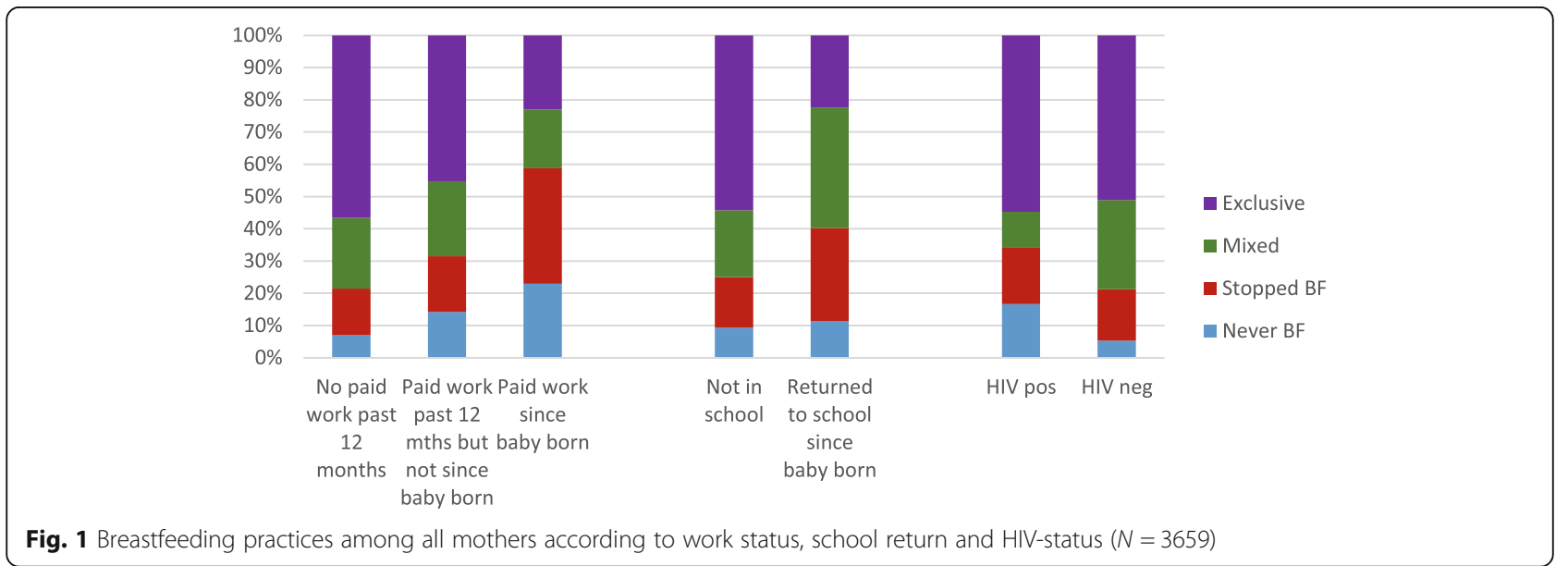


setting there might be a need also in parallel to strengthen the infant-HIV-prophylaxis treatment as an alternative if the mother have delayed PMTCT participation or is non-adherent [49].

\section{Strengths and limitations}

Major strengths were that this study was a large, representative sample of KwaZulu-Natal, a large province in South Africa. Given the high attendance for 14 week immunisation visits, this study provides a good estimate of population level feeding practices in KZN. Inclusion of information from non-maternal caregivers, a group often is excluded in infant feeding studies, added additional strength. The survey design with its comprehensive instruments enabled a risk factor analysis.

The limitations of the study was having a 14 week recall period which can provide information bias as mothers may have had difficulty recalling exactly what her infant was fed. Although we expected limited social desirability recall bias as the research team was independent from the health providers, this can never be eliminated, especially not at facility based studies. A possible limitation was that we assumed there was no design effect at sample size calculation, however the analysis was adjusted for clustering at clinic level.

\section{Conclusion}

This survey from KZN, South Africa highlights an improvement in exclusive breastfeeding practices at 14 weeks of age. Particular challenges to achieving optimal breastfeeding practices at 14 weeks, include the need to improve breastfeeding practices among HIV positive mothers and supporting working or schooling mother to continue giving breastmilk while they are away from their child. However, it is important to note that breastfeeding practices among all mothers are sub-optimal and there is a need to strengthen individualised feeding counselling at the various contact points for pregnant and lactating mothers. In the effort to improve breastfeeding practices for HIV positive women, there is also a need to consider the gap in PMTCT services.

\footnotetext{
Abbreviations

ART: Ante-retroviral therapy; BREC: Biomedical Research Ethics Committee; CHW: Community health worker; Cl: Confidence interval; EBF: Exclusive breastfeeding; HIV: Human Immunodeficiency Virus; IQR: Inter quartile range; KZN: KwaZulu-Natal; KZN-COGTA: KwaZulu-Natal Department of Cooperative Governance and Traditional Affairs; MBF: Mixed breastfeeding; OR: Odds Ratio; PCA: Principal component analysis; PHC: Primary health care; PMTCT: Prevention of mother-to-child HIV transmission; SA: South Africa; SDG: Sustainable development goals; UKZN: University of KwaZulu-Natal; UN: United Nations; Wgt: Weighted; WHO: World health organization
}

\section{Acknowledgements}

We acknowledge Dr. Ben Sartorius for his extremely valuable support with the sampling for this study. We would like to thank the KZN Department of Health at provincial, district and health facility level for their invaluable support during this study. We would like to acknowledge all the many fieldworkers who collected the data. We would particularly like to thank all the mothers who so willingly participated.
Funding

Funding for the study was provided by ELMA Foundation.

Availability of data and materials

The data and study tools that support the findings of this study are available from the Centre for Rural Health and will be made available by the main and corresponding author on reasonable request.

\section{Authors' contributions}

$\mathrm{CH}, \mathrm{LH}, \mathrm{SP}, \mathrm{AC}$ and LS conceptualised the study and $\mathrm{CH}, \mathrm{LH}$ and SP was involved in conducting the study. CH, SP, CC and IE undertook the analysis. $\mathrm{CH}$ and IE wrote the first draft of the manuscript. All authors contributed to critically refining the manuscript and all authors approved the final draft and agreed to be accountable for all aspects of the work presented.

\section{Ethics approval and consent to participate}

Ethics approval was obtained from the Biomedical Research ethics committee (BREC) at UKZN (BE064/14) and from the KZN Department of Health, including permission to enrol mothers aged 15-17 years, to ensure that representation of younger mothers in the sample. Permission to undertake the study was obtained from KZN Department of Health, district managers in all districts, and facility managers in participating clinics. All participants provided written informed consent.

\section{Competing interests}

The authors declare that they have no competing interests.

\section{Publisher's Note}

Springer Nature remains neutral with regard to jurisdictional claims in published maps and institutional affiliations.

\section{Author details}

${ }^{1}$ Centre for Rural Health, University of KwaZulu-Natal, Durban, South Africa. ${ }^{2}$ Centre for International Health, Department of global public health and primary care, University of Bergen, Bergen, Norway. ${ }^{3}$ Department of Paediatrics \& Child Health, School of Clinical Medicine, Nelson R Mandela School of Medicine, University of KwaZulu-Natal , Durban, South Africa. ${ }^{4}$ KwaZulu-Natal Department of Health, Pietermaritzburg, KwaZulu-Natal, South Africa.

Received: 8 February 2018 Accepted: 1 June 2018

Published online: 19 June 2018

\section{References}

1. United Nations Decade of Action on Nutrition [http://www.who.int/ nutrition/decade-of-action/en/]. Accessed 6 June 2018

2. Morgan JJ. aJJ: Factors influencing the infant feeding choices of HIV-positive mothers at a level two hospital in cape town. Afr J Midwifery Womens Health. 2015;9(2):66-70.

3. Victora CG, Bahl R, Barros AJ, Franca GV, Horton S, Krasevec J, Murch S, Sankar MJ, Walker N, Rollins NC, et al. Breastfeeding in the 21st century: epidemiology, mechanisms, and lifelong effect. Lancet. 2016;387(10017):475-90.

4. WHO/UNICEF. Global Nutrition Targets 2025. Geneva: Breastfeeding policy brief (WHO/NMH/NHD/14.7); 2014.

5. Horta BL, Victora CG. Long-term effects of breastfeeding: a systematic review, vol. 74. Geneve: World Health Organization; 2013.

6. Ramokolo V, Lombard C, Chhagan M, Engebretsen IM, Doherty T, Goga AE, Fadnes LT, Zembe W, Jackson DJ, Van den Broeck J. Effects of early feeding on growth velocity and overweight/obesity in a cohort of HIV unexposed south African infants and children. Int Breastfeed J. 2015;10:14.

7. Walfisch A, Sermer C, Cressman A, Koren G. Breast milk and cognitive development-the role of confounders: a systematic review. BMJ Open. 2013;3(8):e003259.

8. Horta BL, Loret de Mola C, Victora CG. Breastfeeding and intelligence: a systematic review and meta-analysis. Acta Paediatr Suppl. 2015;104(467):14-9.

9. Victora CG, Horta BL, Loret de Mola C, Quevedo L, Pinheiro RT, Gigante DP, Goncalves H, Barros FC. Association between breastfeeding and intelligence, educational attainment, and income at 30 years of age: a prospective birth cohort study from Brazil. Lancet Glob Health. 2015;3(4):e199-205. 
10. Chowdhury R, Sinha B, Sankar MJ, Taneja S, Bhandari N, Rollins N, Bahl R, Martines J. Breastfeeding and maternal health outcomes: a systematic review and meta-analysis. Acta Paediatr. 2015;104(S467):96-113.

11. Rollins NC, Bhandari N, Hajeebhoy N, Horton S, Lutter CK, Martines JC, Piwoz EG, Richter LM, Victora CG, Lancet Breastfeeding Series G. Why invest, and what it will take to improve breastfeeding practices? Lancet. 2016; 387(10017):491-504

12. Arpadi S, Fawzy A, Aldrovandi GM, Kankasa C, Sinkala M, Mwiya M. Growth faltering due to breastfeeding cessation in uninfected children born to HIVinfected mothers in Zambia. Am J Clin Nutr. 2009;90(2):344-53.

13. Schwartz SR, Kumwenda N, Kumwenda J, Chen S, Mofenson LM, Taylor AW. Maternal highly active antiretroviral therapy and child HIV-free survival in Malawi, 2004-2009. Matern Child Health J. 2016;20

14. SA Department of Health, Medical Research Council: South African Demographic and Health Survey, 2003. . In. Pretoria; 2007.

15. Thomas TK, Masaba R, Borkowf CB, Ndivo R, Zeh C, Misore A. Tripleantiretroviral prophylaxis to prevent mother-to-child HIV transmission through breastfeeding-the Kisumu breastfeeding study, Kenya: a clinical trial. PLoS Med. 2011;8(3):e1001015.

16. Doherty T, Sanders D, Jackson D, Swanevelder S, Lombard C, Zembe W, Chopra M, Goga A, Colvin M, Fadnes LT, et al. Early cessation of breastfeeding amongst women in South Africa: an area needing urgent attention to improve child health. BMC Pediatr. 2012;12:105.

17. Shifraw T, Worku A, Berhane Y. Factors associated exclusive breastfeeding practices of urban women in Addis Ababa public health centers, Ethiopia: a cross sectional study. Int Breastfeed J. 2015;10:22.

18. Tylleskar T, Jackson D, Meda N, Engebretsen IM, Chopra M, Diallo AH, Doherty T, Ekstrom EC, Fadnes LT, Goga A, et al. Exclusive breastfeeding promotion by peer counsellors in sub-Saharan Africa (PROMISE-EBF): a cluster-randomised trial. Lancet. 2011:378(9789):420-7.

19. Thomas-Jackson SC, Bentley GE, Keyton K, Reifman A, Boylan M, Hart SL. Inhospital breastfeeding and intention to return to work influence Mothers' breastfeeding intentions. J Hum Lact. 2016;32(4):NP76-83.

20. Sudfeld CR, Fawzi WW, Lahariya C. Peer support and exclusive breastfeeding duration in low and middle-income countries: a systematic review and meta-analysis. PLoS One. 2012;7(9):e45143.

21. Jjumba P, Doherty T, Jackson D, Tomlinson M, Sanders D, Swanevelder S, Persson LA. Effect of an integrated community-based package for maternal and newborn care on feeding patterns during the first 12 weeks of life: a cluster-randomized trial in a south African township. Public Health Nutr. 2015;18(14):2660-8.

22. South Africa National Department of Health. 2013 South African national antenatal sentinel HIV prevalence survey. Pretoria: Department of Health; 2013.

23. Chinkonde JR, Sundby J, de Paoli M, Thorsen VC. The difficulty with responding to policy changes for HIV and infant feeding in Malawi. Int Breastfeed J. 2010;5:11.

24. WHO/UNICEF: Guideline: updates on HIV and infant feeding: the duration of breastfeeding, and support from health services to improve feeding practices among mothers living with HIV. In. Geneva; 2016.

25. Massyn N, Day C, Peer N. District Health Barometer 2014/15. Durban: Health Systems Trust, 2015; 2013.

26. Rollins N, Little K, Mzolo S, Horwood C, Newell ML. Surveillance of motherto-child transmission prevention programmes at immunization clinics: the case for universal screening. AIDS (London, England). 2007;21(10):1341-7.

27. Treasury SAN. Local government budgets and expenditure review report in. Pretoria. 2011:2011:191-3.

28. Bland RM, Rollins NC, Solarsh G, Van den Broeck J, Coovadia HM. Maternal recall of exclusive breast feeding duration. Arch Dis Child. 2003;88(9):778-83.

29. Engebretsen IM, Shanmugam R, Sommerfelt AE, Tumwine JK, Tylleskar T. Infant feeding modalities addressed in two different ways in eastern Uganda. Int Breastfeed J. 2010;5(1):2.

30. Piwoz EG. Breastfeeding and replacement feeding practices in the context of mother-to-child transmission of HIV. An assessment tool for research. WHO/RHR/01.12, WHO/CAH/01.21. Geneva: World Health Organization, Department of Reprod Health and Research (RHR), Department of Child and Adolescent Health and Development (CAH); 2001.

31. Jackson DSS, Lombard C, Doherty T, Goga A. Increased exclusive breastfeeding in South Africa from 2010 to 2013: impact of national policy change. South Africa: Priorities in Perinatal Care in Southern Africa Warmbaths; 2016.

32. SA National Department of Health SSA, SA Medical Research Council. 2016 South African Demographic and Health Survey: Key indicator report. In: South African Demographic and Health Survey. Pretoria: SA National Department of Health; 2016.

33. Shisana O, Labadarios D, Rehle T, Simbayi L, Zuma K, Dhansay A, Reddy P, Parker W, Hoosain E, Naidoo P: The south African National Health and nutrition examination survey, 2012: SANHANES-1: the health and nutritional status of the nation: HSRC press; 2014.

34. SA Department of Health, Medical Research Council: South African Demographic and Health Survey, 2016. . In Pretoria; 2017.

35. South African Department of Health. The Tshwane Declaration for the Support of Breastfeeding in South Africa S Afr. J Clin Nutr. 2011;24(4):214.

36. Mandal B, Roe BE, Fein SB. The differential effects of full-time and part-time work status on breastfeeding. Health Policy. 2010;97(1):79-86.

37. Mirkovic KR, Perrine CG, Scanlon KS, Grummer-Strawn LM. Maternity leave duration and full-time/part-time work status are associated with US mothers' ability to meet breastfeeding intentions. J Hum Lact. 2014:30(4):416-9.

38. Bonet M, Marchand L, Kaminski M, Fohran A, Betoko A, Charles M-A, Blondel B. Breastfeeding duration, social and occupational characteristics of mothers in the French 'EDEN mother-Child'Cohort. Matern Child Health J. 2013;17(4): 714-22.

39. Chuang C-H, Chang P-J, Chen Y-C, Hsieh W-S, Hurng B-S, Lin S-J, Chen P-C. Maternal return to work and breastfeeding: a population-based cohort study. Int J Nurs Stud. 2010:47(4):461-74.

40. Addati L, Cassirer N, Gilchrist K: Maternity and paternity at work: law and practice across the world: international labour Office; 2014.

41. Hirani SA, Karmaliani R. Evidence based workplace interventions to promote breastfeeding practices among Pakistani working mothers. Women Birth. 2013;26(1):10-6.

42. Republic of South Africa. Basic Conditions of Employment Act 75 of 1997. In Pretoria: SA government printers; 1997. http://www.labour.gov.za/DOL/ downloads/legislation/acts/basic-conditions-of-employment/Act\%20\%20Basic\%20Conditions\%20of\%20Employment.pdf. Accessed 6 June 2018.

43. Bai DL, Fong DY, Tarrant M. Factors associated with breastfeeding duration and exclusivity in mothers returning to paid employment postpartum. Matern Child Health J. 2015;19(5):990-9.

44. Kumar V, Arora G, Midha IK, Gupta YP. Infant and young child feeding behaviors among working mothers in India: implications for Global Health policy and practice. Int J MCH AIDS. 2015;3(1):7-15.

45. Balogun OO, O'Sullivan EJ, McFadden A, Ota E, Gavine A, Garner CD, Renfrew MJ, MacGillivray S. Interventions for promoting the initiation of breastfeeding. Cochrane Database Syst Rev. 2016;11:CD001688.

46. Jama NA, Wilford A, Masango Z, Haskins L, Coutsoudis A, Spies L, Horwood C. Enablers and barriers to success among mothers planning to exclusively breastfeed for six months: a qualitative prospective cohort study in KwaZulu-Natal, South Africa. Int Breastfeed J. 2017:12:43.

47. Horwood C, Butler L, Barker P, Phakathi S, Haskins L, Grant M, Mntambo N Rollins N. A continuous quality improvement intervention to improve the effectiveness of community health workers providing care to mothers and children: a cluster randomised controlled trial in South Africa. Hum Resour Health. 2017;15(1):39.

48. World Health Organisation, United Nations Childrens Fund. Guideline: Update on HIV and infant feeding: the duration of breastfeeding, and the support from health services to improve feeding practices among mothers living with HIV. Geneva: World Health Organization; 2016. World Health Organization

49. Nagot N, Kankasa C, Meda N, Hofmeyr J, Nikodem C, Tumwine JK, Karamagi C, Sommerfelt H, Neveu D, Tylleskar T, et al. Lopinavir/ritonavir versus lamivudine peri-exposure prophylaxis to prevent HIV-1 transmission by breastfeeding: the PROMISE-PEP trial protocol ANRS 12174. BMC Infect Dis. 2012;12:246 